\title{
Effect of rewetting solutions on micropush-out dentin bond strength of new bioceramic endodontic material
}

\section{Giovana Cunha GRITTI(a) Salma Ivanna Araújo CAVALCANTE $^{(a)}$ \\ Etevaldo Matos MAIA-FILHO(a) José BAUER ${ }^{(b)}$ \\ Matheus Coêlho BANDÉCA(a) \\ Giulio GAVINI(c) \\ Ceci Nunes CARVALHO(a)}

(a) Universidade Ceuma - UNICEUMA, São Luis, MA, Brazil.

(b) Universidade Federal do Maranhão UFMA, Discipline of Dental Materials, São Luis, MA, Brazil.

(c) Universidade de São Paulo - USP, Dental School, Department of Restorative Dentistry, São Paulo, SP, Brazil

Declaration of Interests: The authors certify that they have no commercial or associative interest that represents a conflict of interest in connection with the manuscript.

\section{Corresponding Author:}

Ceci Nunes Carvalho

E-mail: cecicar@usp.br

https://doi.org/10.1590/1807-3107BOR-2017.vol31.0076

Submitted: Feb 27, 2017

Accepted for publication: June 16, 2017

Last revision: July 12, 2017
Abstract: To evaluate the influence of rewetting solutions on bond strength to root dentin of conventional gutta-percha (GP) or niobium phosphate glass-based gutta-percha $(\mathrm{GNb})$ associated with a bioceramic sealer. The root canals of 80 human mandibular premolars were prepared using nickel-titanium instruments and irrigation with sodium hypochlorite and EDTA. The teeth were randomly divided into four groups according to the gutta-percha used: $\mathrm{GNb}$ or GP associated with EndoSequence BC Sealer (BC) and the solution for rewetting dentin before filling (distilled water; phosphate buffer saline solution - PBS; simulated body fluid - SBF; or no solution). The root canals were filled with a single cone using warm vertical condensation. Micropush-out bond strengths associated with the filling materials in slices from middle root thirds was determined 30 days after root filling. The failure mode was analyzed with stereoscopic lens. The data were statistically analyzed by two-way ANOVA and Holm-Sidak test $(p<0.05)$. There was significant difference in the types of gutta-percha $(p<0.001)$ and in the different rewetting solutions $(p=0.003)$. The interaction between gutta-percha and rewetting solutions was not significant $(p=0.53)$. The SBF solution provided an increase in bond strength for both gutta-percha solutions. The $\mathrm{GNb}+\mathrm{BC}(3.42 \mathrm{MPa})$ association increased bond strength when compared with GP+BC (2.0 MPa). The use of SBF as a dentin rewetting solution increased bond strength in the groups studied. Association of $\mathrm{GNb}$ with bioceramic sealer was beneficial, increasing the bond strength to dentin when compared with the association with GP.

Keywords: Endodontics; Gutta-Percha; Niobium; Root Canal Filling Materials; Biomimetic Materials.

\section{Introduction}

The root canal filling stage is an important step for the success of endodontic treatment. In addition to efficiently sealing the root canal system, the filling must not interfere, but preferably stimulate, apical and periapical repair after treatment. ${ }^{1}$

Bioactive glasses associated with polyisoprene, polycaprolactone, or gutta-percha have been presented as an alternative to conventional endodontic filling, by effectively filling the root canal, even in a humid environment without the use of any sealer. ${ }^{2}$ These new composites generally 
contain bioactive glasses capable of releasing ionic species and forming a precipitate, hydroxyapatite, allowing for better sealing by inducing dentin remineralization, in addition to inhibiting microbial biofilm formation. . $3,3,4,5,6,7^{2}$

At present, there are also bioceramic filling sealers on the market. These have been gaining attention because they have greater advantages over the cements considered to be gold standard. ${ }^{8,9,10}$ They are biocompatible, atoxic, do not undergo volumetric shrinkage, are chemically stable, have bioactive potential, and are less cytotoxic and genotoxic,,$^{8,9,10,11}$ and have adequate bonding to root dentin. ${ }^{12}$ These sealers require a certain amount of dentin moisture to set and achieve their best bond strength results. ${ }^{12}$ Nevertheless, there are still no studies relating the combined use of bioceramic sealers and bioactive gutta-percha and their effects on the bond strength to dentin.

The bioactive potential of biomaterials is tested in vitro using a simulated body fluid (SBF) solution that simulates the organic portion of human blood plasma. ${ }^{13}$ In endodontics, however, there is no standard solution for testing bioceramic materials, or any studies that determine what would be the best solution for in vitro simulation of natural dentin moisture in vivo for endodontically treated teeth. Some authors have questioned the use of SBF because it is supersaturated; this may generate false-positive bioactivity results, and they recommend other, i.e. less saturated, types of solutions, such as PBS. ${ }^{5,14}$

Therefore, the aim of this study was to evaluate the influence of rewetting dentin with several solutions on the bond strength of a conventional and an experimental bioactive niobium phosphate glass-based composite and gutta-percha (GNb) associated with a bioceramic sealer.

The null hypothesis was that the different rewetting solutions do not influence the bond strength of conventional gutta-percha and $\mathrm{GNb}$ associated with a bioceramic sealer.

\section{Methodology}

Niobium phosphate glass were prepared according to the previously described protocol. ${ }^{6,15}$ The gutta-percha in powder form (Odous de Deus, Belo Horizonte, Brazil) was placed in a composite chamber for mixing with niobium phosphate glass at increasing concentrations up to a limit of $30 \%$ by the glass-to-polymer ratio and the resultant material was inserted into an extruder (HAAKE MiniLab micro compounder, Newington, USA). The final mixture was rolled manually to give it a convenient shape for use in endodontic filling, that is, in pellets and points (accessory sizes and medium and fine medium points). ${ }^{6}$

\section{SBF preparation}

The SBF was prepared according to the previously described protocol. ${ }^{16}$ During SBF preparation, the solution remained colorless and left no deposits in the container. SBF was stored in a plastic container and kept in a refrigerator at $4^{\circ} \mathrm{C}$.

\section{Root canal preparation and filling}

After the research protocol was approved by the local Research Ethics Committee (CAEE 36709714.3.0000.5084), 80 human mandibular premolars extracted for various reasons were selected. The teeth were subjected to periapical radiographic exams to verify the presence of a single canal; complete rhizogenesis; absence of root caries; localized or diffused calcification; resorptions; or previous endodontic treatment. After removing organic matter from the root surfaces, the teeth were stored for 1 week in flasks containing $0.1 \%$ thymol solution at $4^{\circ} \mathrm{C}$ for microbiological control.

The teeth were sectioned perpendicularly to the long axis, immediately below the cementoenamel junction, with a double-faced flexible diamond disc (KG, Medical Burs Ind. e Com. de Pontas e Brocas Cirúrgicas Ltda, Cotia, Brazil) fitted to a straight handpiece coupled to an LB 100 bench micromotor (Beltec, Araraquara, Brazil).

The working length was determined for each tooth by introducing an endodontic instrument type $\mathrm{K} \# 10$ (Dentsply Maillefer, Ballaigues, Switzerland) into the root canal until the file tip was visualized in the apical foramen, with the aid of a stereoscopic lens at 25x magnification (Baush, Lomb, Rochester, USA), and subtracting $1 \mathrm{~mm}$ from the obtained measurement.

The canals were emptied with type K \#15 files (Dentsply Maillefer, Ballaigues, Switzerland) in the 
presence of 2.5\% sodium hypochlorite (Asfer Indústria Química Ltda., São Caetano do Sul, Brazil). The root canals were prepared with reciprocating kinematic movements of the VDW Silver motor (VDW, Munich, Germany), R40 files (VDW, Munich, Germany), and $10 \mathrm{~mL}$ of $2.5 \%$ sodium hypochlorite, at $\mathrm{pH} 11$. After that, the dentin was chemically treated with $1 \mathrm{~mL}$ of $17 \%$ EDTA for 1 minute and final irrigation with $5 \mathrm{~mL}$ of distilled water. In order to standardize the remaining dentin moisture, the canals were dried with two R40 absorbent paper points (VDW, Munich, Germany).

After chemomechanical preparation, the 80 roots were randomly divided into eight experimental groups $(n=10)$ according to the type of gutta-percha used - experimental niobium phosphate glass-based gutta-percha $(\mathrm{GNb})$ or conventional gutta-percha (GP - Gutta-Percha Reciproc R40, VDW, Munich, Germany), both associated with EndoSequence BC Sealer (BC - Brasseler USA, Savannah, USA) and with the solution for rewetting dentin before filling - distilled water - DW; phosphate buffer saline solution - PBS; simulated body fluid - SBF; or no solution - control).

The canals were irrigated with $0.1 \mathrm{~mL}$ of the rewetting solution, following the protocol for each group, and excess moisture was removed with one R40 absorbent paper point to keep the dentin wet. For the control group, in which no rewetting solution was used, the canals were dried after irrigation with EDTA and distilled water by using R40 absorbent paper points, as previously described (normal moisture condition ${ }^{12}$ ).

The root canals were filled with a single cone using warm vertical condensation by varying the guttapercha and rewetting solutions in each of the previously described groups. The sealer was manipulated in accordance with the manufacturer's instructions.

After filling, all specimens were stored in an oven at $37^{\circ} \mathrm{C}$, in an environment with $100 \%$ moisture for 30 days.

\section{Micropush-out bond strengths}

After the storage period, the roots were cross-sectioned in a cutting machine (Isomet Low Speed Saw, Buehler, Lake Bluff, USA) with a 0.4-mm thick diamond disc under constant cooling, and the most apical and cervical slices were discarded. After these four slices $2.0 \mathrm{~mm}$ thick were obtained from each root. The thickness of slices was measured with a digital caliper with a precision of $0.01 \mathrm{~mm}$ (Mitutoyo MTI Corporation, Tokyo, Japan).

Digital images of both sides of the slices were captured by using a stereoscopic lens at 20X magnification. The apical and cervical diameters were measured with the use of Image J software (National Institute of Health, Maryland, USA, http:/rsb.info.nih.gov/ij/).

The cervical surface of each test specimen was placed on the support coupled to the base of the universal testing machine (EMIC, Instron Brasil Equipamentos Científicos Ltda, São José dos Pinhais, Brazil). Thus, the apical side faced towards a stainless steel cylindrical punch fixed to the 50-kgf load cell. The post diameter was selected so that it could be $0.2 \mathrm{~mm}$ smaller than the apical diameter of the slice, in order to prevent it from touching the dentin walls during the test. The test was performed at a speed of $0.5 \mathrm{~mm} / \mathrm{minute}$ until complete extrusion of the filling, recorded by the abrupt drop in the value of the applied load.

Using the load value in Kgf recorded after the tests, the bond strength values ( $\mathrm{MPa}$ ) were calculated by dividing the maximum force necessary to displace the filling material in Newtons $(\mathrm{N})$ by the area of the bond interface (BS=F/A). Where:

$$
A=\pi(R+r) \sqrt{h^{2}+(R-r)^{2}}
$$

A corresponded to the specimen's surface area; $\pi$ is the constant 3.1416; $\mathbf{R}$ is the largest radius of the cone; $r$ is the smallest radius of the cone, and $\mathbf{h}$ is the slice thickness. ${ }^{17}$

\section{Failure mode analysis}

After the test, the slices were longitudinally cleaved in the buccolingual direction by using a chisel and hammer; and the root segments were examined with a stereoscopic lens (SZ61, Olympus America Inc., City, USA) at 40X magnification to measure the percentage of residual filling material in dentin. The interface area was classified into adhesive, when there was over $75 \%$ dentin free of filling material; cohesive, when there was less than $25 \%$; and mixed, when there was between $25 \%$ and $75 \%$ of exposed dentin. ${ }^{18}$ 


\section{Statistical analysis}

The statistical analysis was performed using the SigmaPlot software 13 (SigmaPlot 13.0; Systat Software Inc., San Jose, USA). Data normality was assessed by the Shapiro-Wilk test, and homogeneity by Levene's test. Two-way ANOVA was used to analyze the micropush-out bond strength, considering the gutta-percha and rewetting solutions as the main factors. The Holm-Sidak test for significant difference was used to compare individual data, and the level of significance was set at $\alpha=0.05$.

\section{Results}

The averages and standard deviations of micropush-out bond strengths (MPa) are shown in Figure 1. The two-way ANOVA did not detect statistically significant differences for the interaction between gutta-percha and the rewetting solutions $(p=0.53)$. There was significant difference for the gutta-percha $(p<0.001)$ and rewetting solutions $(p=0.003)$. The GNb increased bond strength when compared to GP $(\mathrm{p}<0.001)$. Regarding the rewetting solutions, SBF had the highest bond strength when compared to the other groups (PBS, DW, and control). The PBS, DW and control groups were similar to each other. The failure mode distributions under all tested conditions are depicted in Figure 2. Cohesive fracture predominated in all groups (Figures 3-5).

\section{Discussion}

This study revealed that the groups in which theSBF rewetting solution was used showed the highest bond strength. Furthermore, the association of experimental bioactive gutta-percha $(\mathrm{GNb})$ with BC Sealer $(\mathrm{BC})$ showed higher bond strength when compared with those of the association with conventional gutta-percha (GP); thus, the null hypothesis was rejected.

In a previous study, experimental GNb showed self-adhesiveness to the surface when the dentin was rewetted with SBF without the use of sealer, showing a similar performance to that of the group in which AH Plus was combined with conventional gutta-percha, ${ }^{6}$ suggesting the experimental material had a self-adhesive capacity originating from the bioactive potential of the niobium phosphate glass associated with gutta-percha. Previously reported data related to another experimental material (Bio-Gutta), with the addition of $45 \mathrm{~S} 5$ bioglass to gutta-percha, presented similar bond strength values when also evaluated by the micropush-out test after 30 days in PBS. ${ }^{5}$ The mechanism of action that enables Bio-Gutta and $\mathrm{GNb}$ materials to bond to dentin is, however, still questionable, and requires further studies.

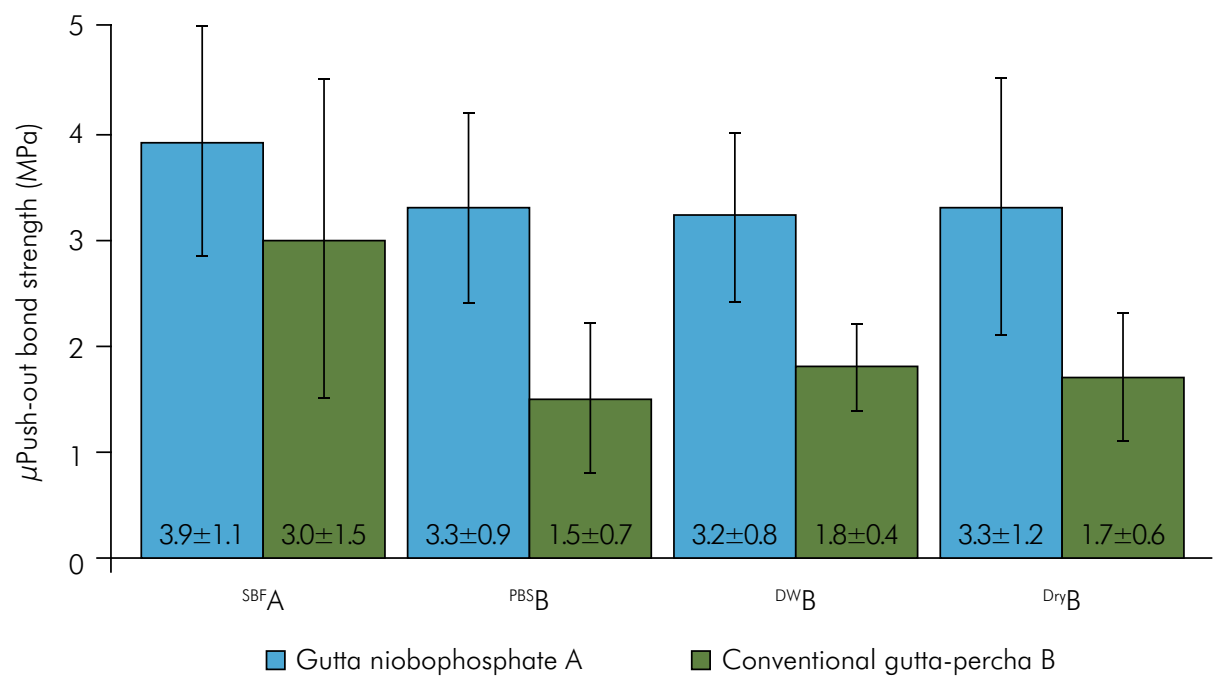

* Different letters in each main factor (gutta-percha and rewetting solutions) show statistically significant difference ( $p<0.05)$.

Figure 1. Mean bond strength (MPa) values for the evaluated gutta-percha and rewetting solutions. 


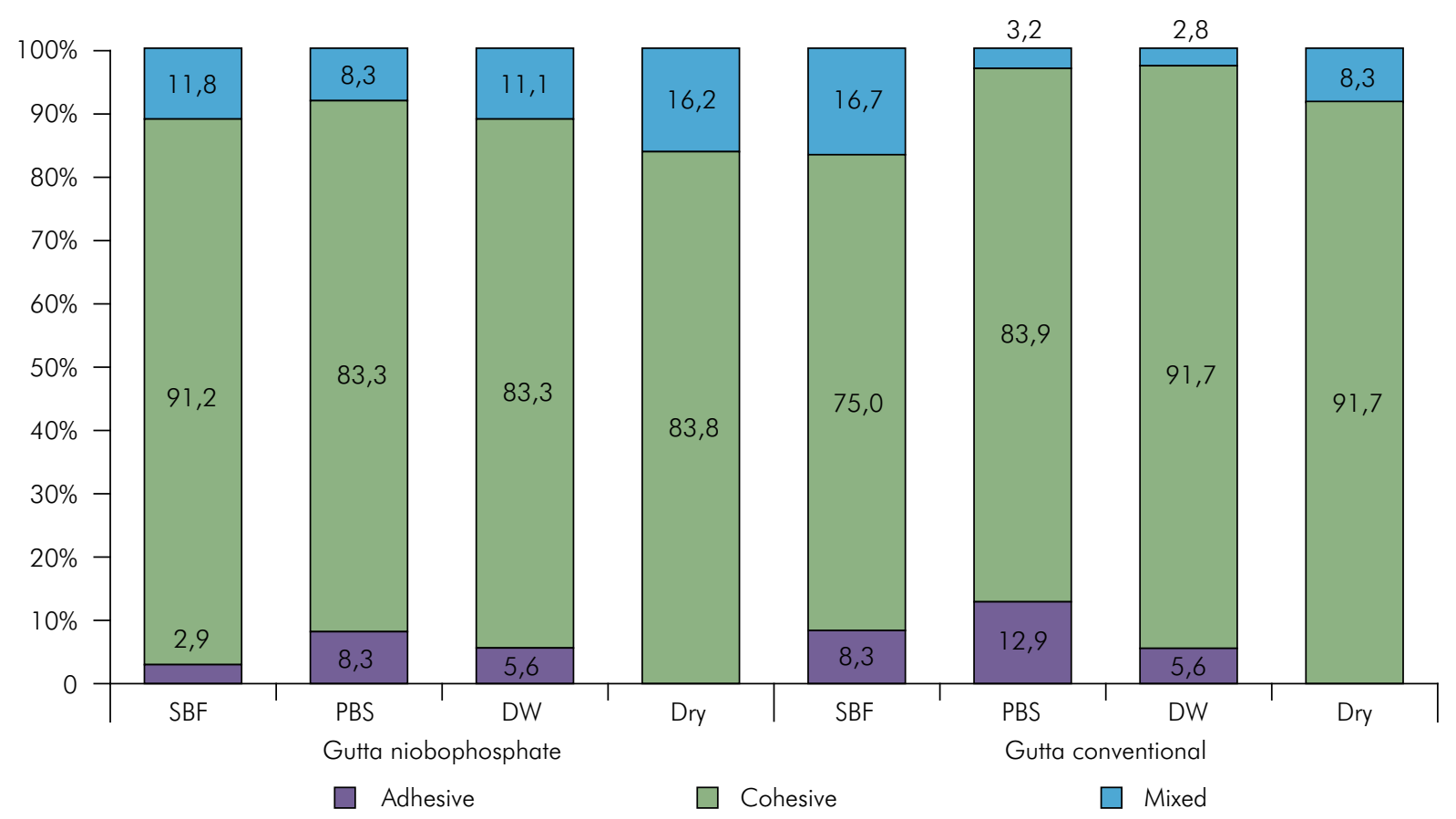

Figure 2. Failure mode distribution per group, expressed in percentage (\%).

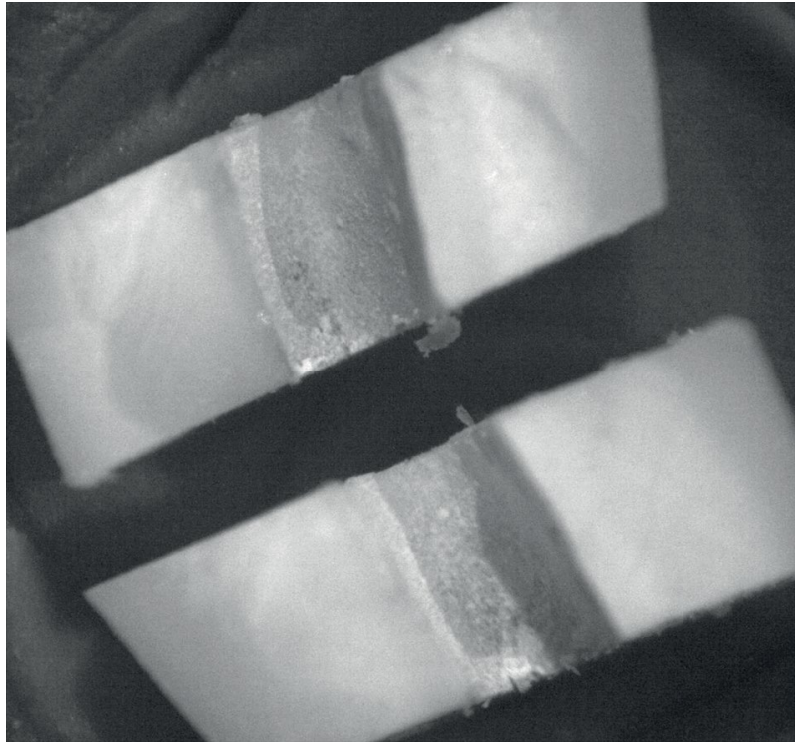

Figure 3. Failure mode classified as adhesive.

At present, there are no studies in the literature evaluating the bond strength of the combined use of bioceramic sealer and bioactive gutta-percha. Association of these materials in this study was shown to be beneficial. The authors could hypothesize that there was some interaction between the two

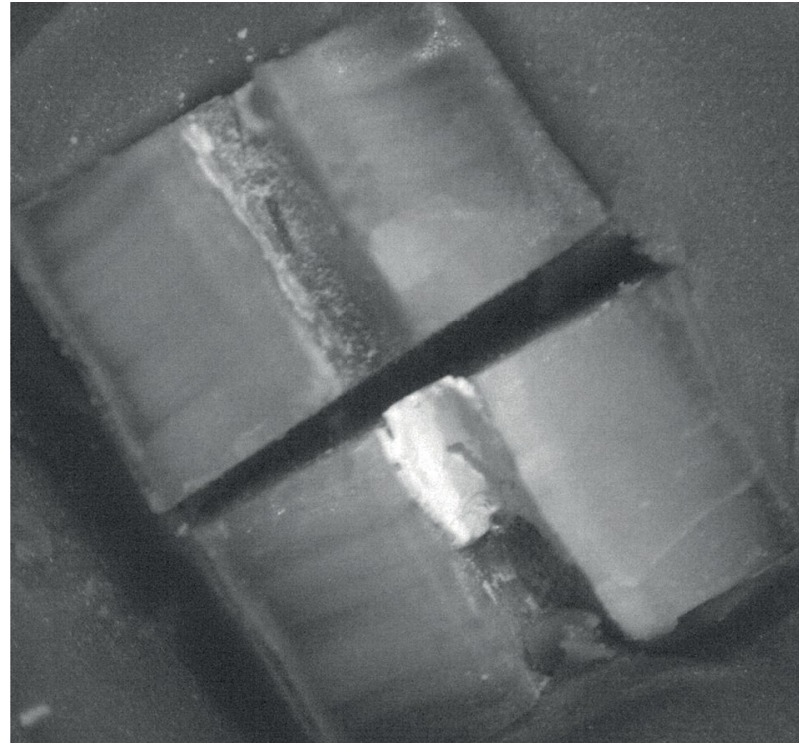

Figure 4. Failure mode classified as mixed.

materials, due to the fact that the silicate-based sealers presented high levels of bioactivity, ${ }_{1}^{19}$ and the experimental gutta-percha in question also had bioactive potential, ${ }^{6}$ which could have been reinforced by precipitate formation at the dentin/sealer and sealer/cone interfaces, increasing bond strength. 


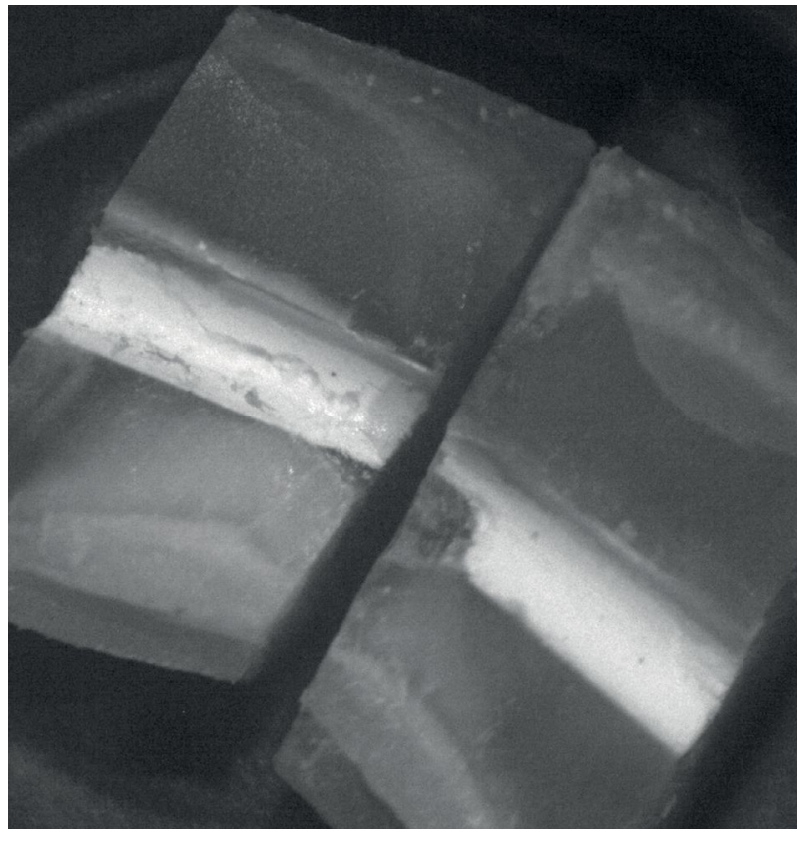

Figure 5. Failure mode classified as cohesive within sealer.

Also, the incorporation of bioactive glasses at a high concentration (around 30\% w/v) could increase the intrinsic strength of the material, contributing to the increase in bond strength to dentin obtained with the $\mathrm{GNb}$ and sealer association. The addition of niobium phosphate glass to gutta-percha could also increase the radiopacity of the material. ${ }^{20}$

The bioactivity of biomaterials is generally tested in vitro, using an SBF solution that simulates the inorganic portion of human blood plasma, with similar ionic concentrations maintained under the same $\mathrm{pH}$ and temperature conditions. ${ }^{16} \mathrm{SBF}$ reacts with the bioactive glass surface, forming a hydroxyapatite layer responsible for the interactions within the hard and soft tissues that promotes a chemical bond of the biomaterial to bone. ${ }^{16,19}$ In endodontics, however, there is no standard solution for testing bioceramic materials in vitro.

Nevertheless, some studies have shown that the use of phosphate-containing solutions may promote the precipitation of carbonated apatites and amorphous calcium phosphates in calcium silicate-based cements, indicating bioactivity of the material. ${ }^{21,22}$ This carbonated apatite represents the biological apatite phases that are found in bone, cement, and dentin. ${ }^{22}$
In the present study, the use of different rewetting solutions simulated the conditions of dentin moisture. Under in vivo conditions, the root dentin of endodontically treated teeth has a moisture level of $12.1 \%,{ }^{23}$ and this moisture is perhaps insufficient to promote the bioactivity of materials within the root canal. Reys-Carmona et al. ${ }^{24,25}$ suggested the use of PBS as intracanal medication to promote biomineralization of MTA apical plugs in the interior portion of root canals, since the biomineralization of MTA can only be achieved in direct contact with the periodontium and dentin.

In the same way, the results of the present study showed that the use of SBF for rewetting dentin promoted the highest bond strength when compared with other less saturated solutions, such as PBS, distilled water, and with no type of solution. From a clinical perspective, it would perhaps be interesting if, together with the bioceramic filling material, the manufacturer supplied a flask of sterile rewetting solution with a composition similar to that of SBF.

According to Marending et al., ${ }^{5}$ SBF has been pointed out to be a supersaturated solution in comparison with hydroxyapatite, so that the precipitates formed on the dentin surface may arise from the solution and not from the bioactivity of the material itself. ${ }^{14}$ The author recommends the use of calcium-free PBS for rewetting root dentin. ${ }^{5}$

The biomineralization process may be responsible for the increase in the marginal sealing of MTA apical plugs over time, after immersion in PBS. ${ }^{26}$ Along the same line, various studies have shown an increase in resistance to the displacement of MTA from root dentin under wet dentin conditions s $^{27,28,29}$ and that the biomineralization process positively influences the bond strength to push-out of MTA cements in PBS. ${ }^{30}$ The authors could hypothesize that, in the present study, SBF promoted a higher degree of bioactivity because it was more supersaturated than the other solutions used; and that the precipitate formed may have influenced the interaction of the filling materials with root dentin, potentiating the bond strength of this bond interface.

While, for some conventional sealers, an environment with excessive moisture appears to be a problem, ${ }^{15,31,32}$ leaving the root canal wet before filling it with 
bioactive materials was shown to be beneficial. ${ }^{15}$ However, more important than the moisture of the root canal is the type of solution, which is more critical in terms of bond strength, as demonstrated by the present study.

Standardization of rewetting solutions for testing bioceramic materials in vitro in endodontics is important and must be further investigated. The association of bioceramic materials appears to be beneficial; however, further studies must be conducted to evaluate this interaction and verify

\section{References}

1. Schwartz RS. Adhesive dentistry and endodontics. Part 2: bonding in the root canal system: the promise and the problems: a review. J Endod. 2006;32(12):1125-34. https://doi.org/10.1016/i.joen.2006.08.003

2. Alani A, Knowles JC, Chrzanowski W, Ng YL, Gulabivala K. Ion release characteristics, precipitate formation and sealing ability of a phosphate glass-polycaprolactone-based composite for use as a root canal obturation material. Dent Mater. 2009;25(3):400-10. https://doi.org/10.1016/j.dental.2008.10.010

3. Mohn D, Bruhin C, Luechinger NA, Stark WJ, Imfeld T, Zehnder M. Composites made of flame-sprayed bioactive glass 45S5 and polymers: bioactivity and immediate sealing properties. Int Endod J. 2010;43(11):1037-46. https://doi.org/10.1111/j.1365-2591.2010.01772.x

4. Mohn D, Zehnder M, Imfeld T, Stark WJ. Radio-opaque nanosized bioactive glass for potential root canal application: evaluation of radiopacity, bioactivity and alkaline capacity. Int Endod J. 2010;43(3):210-7. https://doi.org/10.1111/j.1365-2591.2009.01660.x

5. Marending M, Bubenhofer SB, Sener B,

De-Deus $G$. Primary assessment of a self-adhesive gutta-percha material. Int Endod J. 2013;46(4):317-22. https://doi.org/10.1111/j.1365-2591.2012.02117.x

6. Carvalho CN, Martinelli JR, Baver J, Haapasalo M., Shen Y, Bradaschia-Correa $V$ et al. Micropush-out dentine bond strength of a new gutta-percha and niobium phosphate glass composite. Int Endod J. 2015;48(5):451-9. https://doi.org/10.1111/iej.12334

7. Carvalho CN, Wang Z, Shen Y, Gavini G, Martinelli JR, Manso $\mathrm{A}$ et al. Comparative analyses of ion release, $\mathrm{pH}$ and multispecies biofilm formation between conventional and bioactive gutta-percha. Int Endod J. 2016;49(11):1048-1056. https://doi.org/10.1111/iej.12558 the real mechanism of action between the different interfaces of the filling.

\section{Conclusion}

The use of SBF as a dentin rewetting solution increased bond strength in the studied groups. The association of bioactive niobium phosphate gutta-percha with bioceramic sealer was beneficial, increasing bond strength to dentin when compared with the association with conventional gutta-percha.
8. Zhang W, Li Z, Peng B. Assessment of a new root canal sealer's apical sealing ability. Oral Surg Oral Med Oral Pathol Oral Radiol Endod. 2009;107(6):e79-82. https://doi.org/10.1016/j.tripleo.2009.02.024

9. Loushine BA, Bryan TE, Looney SW, Gillen BM, Loushine RJ, Weller RN et al. Setting properties and cytotoxicity evaluation of a premixed bioceramic root canal sealer. J Endod. 2011;37(5):673-7. https://doi.org/10.1016/i.joen.2011.01.003

10. Candeiro GT, Moura-Netto C, D'Almeida-Couto RS, Azambuja-Júnior N, Marques MM, Cai S et al. Cytotoxicity, genotoxicity and antibacterial effectiveness of a bioceramic endodontic sealer. Int Endod J. 2015 Aug. https://doi.org/10.1111/iej.12523

11. Candeiro GTM, Correia FC, Duarte MAH, Ribeiro-Siqueira DC, Gavini G. Evaluation of radiopacity, $\mathrm{pH}$, release of calcium ions and flow of a bioceramic root canal sealer. J Endod. 2012;38(6):842-5. https://doi.org/10.1016/i.joen.2012.02.029

12. Nagas E, Uyanik MO, Eymirli A, Cehreli ZC, Vallittu PK, Lassila LV et al. Dentin moisture conditions affect the adhesion of root canal sealers. J Endod. 2012;38(2):240-4. https://doi.org/10.1016/i.joen.2011.09.027

13. Kokubo T, Kushitani H, Sakka S, Kitsugi T, Yamamuro T. Solutions able to reproduce in vivo surface-structure changes in bioactive glass-ceramic A-W. J Biomed Mater Res. 1990;24(6):721-34. https://doi.org/10.1002/jbm.820240607

14. Bohner M, Lemaitre J. Can bioactivity be tested in vitro with SBF solution? Biomaterials. 2009;30(12):2175-9. https://doi.org/10.1016/i.biomaterials.2009.01.008

15. Carbonari JM, Faria Jr LJ, Kronig Jr B, Martinelli JR. Bioactive niobium phosphate glasses for osseointegrated applications. 2004. Brazil WO2004026781A1. 2004 Apr 1.

16. Kokubo T, Takadama H. How useful is SBF in predicting in vivo bone bioactivity? Biomaterials. 2006;27(15):2907-15. https://doi.org/10.1016/i.biomaterials.2006.01.017 
17. Patierno JM, Rueggeberg FA, Anderson RW, Weller RN, Pashley DH. Push-out strength and SEM evaluation of resin composite bonded to internal cervical dentin.

Endod Dent Traumatol. 1996;12(5):227-36. https://doi.org/10.1111/ן.1600-9657.1996.tb00520.x

18. Fowler CS, Swartz ML, Moore BK, Rhodes BF. Influence of selected variables on adhesion testing. Dent Mater. 1992;8(4):265-9. https://doi.org/10.1016/0109-5641(92)90097-V

19. Han L, Okiji T. Bioactivity evaluation of three calcium silicate-based endodontic materials. Int Endod J. 2013;46(9):808-14. https://doi.org/10.1111/iej.12062

20. Baver J, Carvalho EM, Carvalho CN, Meier MM, Souza JP, Carvalho RM et al. Development of a simplified etch-and-rinse adhesive containing niobiophosphate bioactive glass. Int J Adhes Adhes. 2016;69:110-4 https://doi.org/10.1016/j.ijadhadh.2016.03.015

21. Bozeman TB, Lemon RR, Eleazer PD. Elemental analysis of crystal precipitate from gray and white MTA. J Endod. 2006;32(5):425-8. https://doi.org/10.1016/i.joen.2005.08.009

22. Tay FR, Pashley DH, Rueggeberg FA, Loushine RJ, Weller RN. Calcium phosphate phase transformation produced by the interaction of the portland cement component of white mineral trioxide aggregate with a phosphate-containing fluid. J Endod. 2007;33(11):1347-51. https://doi.org/10.1016/i.joen.2007.07.008

23. Papa J, Cain C, Messer HH. Moisture content of vital vs endodontically treated teeth. Endod Dent Traumatol. 1994;10(2):91-3. https://doi.org/10.1111/j.1600-9657.1994.tb00067.x

24. Reyes-Carmona JF, Felippe MCS, Felippe WT. Biomineralization ability and interaction of mineral trioxide aggregate and white portland cement with dentin in a phosphate-containing fluid. J Endod. 2009;35(5):731-6. https://doi.org/10.1016/j.joen.2009.02.011
25. Reyes-Carmona JF, Felippe MS, Felippe WT.

A phosphate-buffered saline intracanal dressing improves the biomineralization ability of mineral trioxide aggregate apical plugs. J Endod. 2010 Oct;36(10):1648-52. https://doi.org/10.1016/i.joen.2010.06.014

26. Martin RL, Monticelli F, Brackett WW, Loushine RJ, Rockman RA, Ferrari $\mathrm{M}$ et al. Sealing properties of mineral trioxide aggregate orthograde apical plugs and root fillings in an in vitro apexification model. J Endod. 2007;33(3):272-5. https://doi.org/10.1016/i.joen.2006.11.002

27. Loxley EC, Liewehr FR, Buxton TB, McPherson JC 3rd. The effect of various intracanal oxidizing agents on the push-out strength of various perforation repair materials. Oral Surg Oral Med Oral Pathol Oral Radiol Endod. 2003;95(4):490-4. https://doi.org/10.1067/moe.2003.32

28. Vanderweele RA, Schwartz SA, Beeson TJ. Effect of blood contamination on retention characteristics of MTA when mixed with different liquids. J Endod. 2006;32(5):421-4. https://doi.org/10.1016/i.joen.2005.09.007

29. Gancedo-Caravia L, Garcia-Barbero E. Influence of humidity and setting time on the push-out strength of mineral trioxide aggregate obturations. J Endod. 2006;32(9):894-6. https://doi.org/10.1016/i.joen.2006.03.004

30. Reyes-Carmona JF, Felippe MCS, Felippe WT. The biomineralization ability of mineral trioxide aggregate and Portland cement on dentin enhances the push-out strength. J Endod. 2010;36(2):286-91. https://doi.org/10.1016/i.joen.2009.10.009

31. Roggendorf MJ, Ebert J, Petschelt A, Frankenberger R. Influence of moisture on the apical seal of root canal fillings with five different types of sealer. J Endod. 2007;33(1):31-3. https://doi.org/10.1016/i.joen.2006.07.006

32. Zmener $\mathrm{O}$, Pameijer $\mathrm{CH}$, Serrano SA, Vidueira $M$, Macchi RL. Significance of moist root canal dentin with the use of methacrylate-based endodontic sealers: an in vitro coronal dye leakage study. J Endod. 2008;34(1):76-9. https://doi.org/10.1016/i.joen.2007.10.012 